\title{
Can family history be used as a tool for public health and preventive medicine?
}

\author{
Paula W. Yoon, ScD, MPH ${ }^{1}$, Maren T. Scheuner, MD, MPH', Kris L. Peterson-Oehlke, MS, CGC ${ }^{1}$,
} Marta Gwinn, MD, MPH ${ }^{1}$, Andrew Faucett, MS, CGC ${ }^{3}$, and Muin J. Khoury, MD, PhD ${ }^{1}$

Most common chronic diseases are the result of complex interactions between multiple genetic variants and environmental factors. Despite significant advances in the last decade in the understanding of our genome, there are substantial limitations in epidemiological and analytic approaches to studying the effects of genetic determinants of common chronic diseases. Knowledge of genetic variation underlying disease susceptibility should improve our ability to diagnose, manage, and prevent these disorders. To date, however, DNA-based testing is limited for the most part to analysis of highly penetrant single gene disorders that account for approximately $5 \%$ of the total disease burden in the population..$^{1,2}$ It may be years before DNA-based tests are routinely applied to predict the onset of common diseases, their natural history, and response to therapy.

In the absence of genetic testing, we postulate that family history can be used as a tool to stratify risk for common chronic diseases and thereby identify individuals with increased disease susceptibility. Could disease information about people's close relatives be used to predict their risk for specific diseases? And, if this can be done with some degree of reliability, would individuals who may be at above average risk benefit from targeted prevention and screening programs beyond what is recommended for the population at large, including DNA-based testing? Further, would individuals found by family history to be at increased risk be more accepting of recommendations about lifestyle changes and participation in heightened early detection and prevention strategies? The purpose of this paper is to introduce the concept of family history as a public health tool for risk stratification leading to improved disease prevention and to describe an evaluation process that would be necessary to determine the feasibility, validity, and utility of this approach.

\section{FAMILY HISTORY AS A RISK FACTOR FOR DISEASE}

Family history of specific diseases reflects the consequences of genetic susceptibilities, shared environment, and common

\footnotetext{
From the ${ }^{1}$ Office of Genomics and Disease Prevention, National Center for Environmental Health, Centers for Disease Control and Prevention, Atlanta, Georgia; ${ }^{2}$ GenRISK Program, Cedars-Sinai Medical Center, Los Angeles, California; and ${ }^{3}$ Division of Laboratory Systems, Public Health Practice Program Office, Centers for Disease Control and Prevention, Atlanta, Georgia.

Paula W. Yoon, ScD, MPH, Office of Genomics and Disease Prevention, CDC/NCEH, MS K-28, 4770 Buford Highway, Atlanta, GA 30341-3724.

Received: February 13, 2002.

Accepted: April 23, 2002.
}

behaviors. The scope of family history information ranges from knowing a parent or sibling had a specific disease to very detailed pedigree analyses about disease and age at onset for first-, second-, and even third-degree relatives. In some families, highly penetrant genetic mutations are transmitted through generations, resulting in a high likelihood of disease. Breast cancer associated with $B R C A 1$ and $B R C A 2$ gene mutations is an example of inherited susceptibility where the disease risk is high. ${ }^{3}$ Fortunately, these deleterious gene mutations are rare in the population. For the majority of families, genetic susceptibility is transmitted through many low penetrant genes that interact with environmental factors to increase the risk for disease. For example, an increasing number of studies are showing that polymorphisms for genes that code for carcinogen metabolizing enzymes (e.g., NAT2 and MGMT) can increase the risk of cancer. ${ }^{4}$ The difficulty of applying genetic tests of such polymorphisms to predict future disease is that each gene variant accounts for only a small increase in risk. Thus, these polymorphisms serve as poor screening tools for predicting disease risk within the general population. ${ }^{5}$ However, testing for these polymorphisms in individuals with a family history of disease could further refine risk, because familial clustering of disease typically reflects multifactorial inheritance in which susceptibility is determined by the combined effects of a number of genes interacting with environmental and lifestyle factors.

Family history has been shown to be a risk factor for a majority of chronic diseases of public health significance, including cardiovascular disease, diabetes, several cancers, osteoporosis, and asthma (Table 1). Most early cardiovascular-related events (coronary heart disease, stroke, hypertension, and diabetes) in the population occur in families with a positive family history of cardiovascular disease. ${ }^{6}$ The late Dr. Roger Williams and his colleagues conducted extensive studies on the use of family history information for predicting future risk of coronary heart disease (CHD). In a large cohort in Utah, they found that having two or more first-degree relatives with CHD identified $8 \%$ of the population with relative risks of 3.3 to 5.9 for CHD before age 50.7 Generally, family history of a common, chronic disease is associated with relative risks ranging from 2 to 5 times those of the general population. ${ }^{8}$ Even greater increase in relative risk is associated with an increasing number of affected relatives and earlier ages of disease onset.

Evidence suggests that family history by itself is most useful for predicting disease when there are multiple family members affected, the relationship among relatives is close, and disease is 
Table 1

Prevalence and relative risk estimates due to family history for selected diseases

\begin{tabular}{|c|c|c|}
\hline Disease & U.S. prevalence of the disease & Risk due to family history \\
\hline \multirow[t]{2}{*}{ Cardiovascular disease } & 58 million & $\mathrm{OR}=2.0$ (one 1st-degree relative $)^{38}$ \\
\hline & & $\mathrm{OR}=5.4(\text { two or more } 1 \text { st-degree relatives with onset }<55 \mathrm{yr})^{39}$ \\
\hline \multirow[t]{2}{*}{ Breast cancer } & 3 million women & $\mathrm{RR}=2.1$ (one 1st-degree relative $)^{40}$ \\
\hline & & $\mathrm{RR}=3.9(\text { three or more } 1 \text { st-degree relatives })^{41}$ \\
\hline \multirow[t]{2}{*}{ Colorectal cancer } & Yearly incidence $=130,000$ & $\mathrm{OR}=1.7$ (one 1st-degree relative $)^{26}$ \\
\hline & & $\mathrm{OR}=4.9(\text { two } 1 \text { st-degree relatives })^{27}$ \\
\hline \multirow[t]{2}{*}{ Prostate cancer } & Yearly incidence $=200,000$ & $\mathrm{RR}=3.2(\text { one } 1 \text { st-degree relative })^{42}$ \\
\hline & & $\mathrm{RR}=11.0$ (three 1 st-degree relatives) ${ }^{43}$ \\
\hline \multirow[t]{2}{*}{ Melanoma } & 200,000 & $\mathrm{OR}=2.7(\text { one or more } 1 \text { st-degree relative })^{44}$ \\
\hline & & $\mathrm{OR}=4.3$ (one 1st-degree relative) ${ }^{45}$ \\
\hline \multirow[t]{2}{*}{ Type II diabetes } & 13 million & $\mathrm{RR}=2.4$ (mother) $)^{46}$ \\
\hline & & $\mathrm{RR}=4.0$ (maternal and paternal relatives) ${ }^{47}$ \\
\hline \multirow[t]{2}{*}{ Osteoporosis } & 8 million women & $\mathrm{OR}=2.0$ for osteoporotic fracture (female 1 st-degree relative $)^{48}$ \\
\hline & 2 million men & $\mathrm{RR}=2.4$ for wrist fracture $(\text { father })^{49}$ \\
\hline \multirow[t]{2}{*}{ Asthma } & 17 million & $\mathrm{OR}=3.0(\text { mother })^{50}$ \\
\hline & & 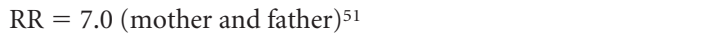 \\
\hline
\end{tabular}

premature, that is, it occurs at younger ages than would be expected. ${ }^{9}$ Although these characteristics of family history can identify people at high risk for disease, they are not typical of the majority of people with chronic disease in the population. Of interest is whether a less extreme family history could be useful as a public health tool for identifying a larger proportion of the population who is at moderate risk for disease.

\section{CLASSIFICATION INTO RISK GROUPS}

A number of methods have been proposed for quantifying the risk associated with family history of disease. Hunt and colleagues developed a family history score that compares a family's age- and sex-specific disease incidence to that expected in the general population and predicts future disease incidence in unaffected family members. ${ }^{7}$ Scheuner and colleagues proposed a classification system that stratifies risk into three groups: high, moderate, and average (general population risk) (Table 2). This classification took into consideration the age of onset of a disease, the number of affected relatives, and their relationship to the patient. Family history data were collected on 400 healthy individuals for 8 chronic conditions: heart disease, stroke, diabetes, colon cancer, breast cancer, endometrial cancer, ovarian cancer, and prostate cancer. Most individuals had an average (general population) risk for these disorders, but approximately $5 \%$ to $15 \%$ of the people were at moderate risk and $1 \%$ to $10 \%$ were at high risk. ${ }^{9}$ Silberberg and colleagues reviewed the literature on the methodology used to calculate family history scores for coronary heart disease. ${ }^{10}$ They evaluated 15 published scores according to several desirable properties of family history scores for common diseas- es-a score should: a) consider the risk profile of the family (taking into account covariates, such as age, sex, smoking status); b) be robust to family size and time at risk; c) consider relationship of the relatives (close relatives being given more weight); and d) not be inflated by a single individual. The authors concluded that all of the published scores performed similarly in distinguishing cases and controls and that all formulations were disadvantaged to the same extent. They recommended that researchers consider characteristics of their data before selecting any particular score formulation and that if families are small and affected relatives are few, categorical definitions or simple counts are likely to be adequate.

\section{FAMILY HISTORY AS A PUBLIC HEALTH TOOL}

Family history has been recognized in clinical medicine as an important, yet nonmodifiable, disease risk factor that when present might influence the probability of a suspected diagnosis. Collection and interpretation of family history has rarely been applied in the practice of preventive medicine to assess disease risk and influence early detection and prevention strategies. In this setting, pedigree analysis has primarily been limited to rare cases of cancer or cardiovascular disease where a strong genetic component is obvious. Even when there is a strong family history, many of these high-risk people who could benefit from a genetic evaluation are missed by their primary care physicians. ${ }^{11}$ People at moderate-risk based on family history are even less likely to be identified. Henderson and Scheuner report on a study of managed care members where 53 charts from 15 primary care physicians selected randomly were reviewed for family history. ${ }^{12}$ This included data 
Table 2

Suggested guidelines for risk stratification based on family history

High risk

1. Premature disease in a 1st-degree relative

2. Premature disease in a 2nd-degree relative (coronary artery disease only)

3. Two affected 1st-degree relatives

4. One 1st-degree relative with late or unknown disease onset and an affected 2nd-degree relative with premature disease from the same lineage

5. Two 2nd-degree maternal or paternal relatives with at least one having premature onset of disease

6. Three or more affected maternal or paternal relatives

7. Presence of a "moderate risk" family history on both sides of the pedigree

Moderate risk

1. One 1st-degree relative with late or unknown onset of disease

2. Two 2nd-degree relatives from the same lineage with late or unknown disease onset

Average risk

1. No affected relatives

2. Only one affected 2nd-degree relative from one or both sides of the pedigree

3. No known family history

4. Adopted person with unknown family history

From Scheuner et al. ${ }^{9}$

collected from 223 patient visits (4.2 visits per patient) that occurred over a 5-year period. Among the charts reviewed, 39 belonged to subjects who gave self-reports of a family history of at least one common disease; the physician recorded this family history in only $36 \%$. The number of first-degree relatives that were reported by patients as having one of the conditions under study was 115 , compared with only 23 recorded by the physician. The corresponding number of self-reported affected second-degree relatives was 213 , and the physicians recorded only 4 . The type of disease did not influence the family history recorded by the physician. Acheson et al. ${ }^{13}$ have found that family practice physicians discuss family history about half of the time during new patient visits, and only $22 \%$ of the time during established patient visits. This included discussion of "family issues" that might represent a broad range of topics in addition to medical issues. The quality of information collected was likely limited (although this was not determined) because the average duration of family history discussions was $<2.5$ minutes. Only $11 \%$ of patients' records included a family tree.

If it can be shown that family history can aid in risk stratification, improve early detection and disease prevention, and influence health promoting behaviors, then family history could be used as a screening tool to find high- and moderaterisk people who would benefit from more targeted interventions. Individuals and families could be encouraged to main- tain their own family health histories and share that information with their clinicians who should also be tracking and updating their patients' family health histories. Keeping a record of family medical history could be as routine as keeping a child's immunization schedule.

Some have argued, however, that placing people in risk groups may lead those in the "average population risk group" to become complacent about health promoting behaviors. ${ }^{14}$ The population-wide approach seeks to convince all people to modify their unhealthy exposures and increase health-promoting behaviors. ${ }^{15}$ It is thought that some people will benefit more than others, but the overall shift in the population will be toward better health. However, most people also appreciate individual differences in disease susceptibility. Prescribing a generic prevention program that does not recognize differences could lead to limited results, discouragement, and noncompliance. Targeting higher risk people for prevention efforts that would be cost-prohibitive at the population level, such as referral for genetic consultation and testing, earlier or more frequent screening, removal from environmental or occupational risk factors, or the use of medications, could prove to be cost-effective. ${ }^{16}$

Would individualizing risk empower people at above average risk to seek medical advice and to practice healthy behaviors? Certainly, it could be argued that our current public health approaches to promoting healthy lifestyles that are targeted to the population-at-large have not been entirely successful. Recent studies reveal that $61 \%$ of Americans are overweight, $23 \%$ of people still smoke, and only $25 \%$ of adults engage in recommended physical activity levels. ${ }^{17-19}$ And the prevalence of obesity and diabetes are increasing in the United States. ${ }^{18}$ If people could be convinced on a more personal level of their need to improve their health based on a family history of chronic disease (and almost all of us have some family history of disease), they may be more likely to engage in healthy behaviors. From a public health perspective, there could be additional benefits. Because many lifestyle choices and behaviors that reduce risk are similar across a wide variety of chronic conditions, there may be a spillover effect where risk is reduced simultaneously for a number of conditions.

\section{VALIDATION OF FAMILY HISTORY FOR PREDICTING DISEASE}

To be useful in public health settings, a family history tool must be simple, easily applied, and inexpensive. Family history has been shown to be a risk factor in many case-control studies (see Table 1), but a systematic evaluation of disease-specific family history information for disease risk stratification and prediction has not been done. A singular family history tool could include a number of common chronic diseases and conditions. Criteria for inclusion of diseases would include the accuracy with which the disease could be recalled, the prevalence of the disease in the population, the risk associated with family history, and the availability of effective early detection and prevention measures.

Before family history can be embraced as a public health screening strategy, a number of critical issues should be ad- 
dressed. The evaluation of a family history tool would not be that different from the evaluation of predictive genetic tests. In 2000, the Secretary's Advisory Committee on Genetic Testing (SACGT) recommended a process for assessing the benefits and risks for genetic tests. ${ }^{20}$ The four components included analytic validity, clinical validity, clinical utility, and ethical, legal, and social issues that influence both validity and utility. The SACGTs recommendations were intended primarily to enhance the way in which genetic tests are developed, reviewed, and used in clinical practice. Likewise, the purpose for a similar evaluation of a family history tool would be to determine the accuracy and reliability of the tool for stratifying disease risk and the effectiveness of this risk stratification on early detection and prevention efforts.

\section{ANALYTIC VALIDITY}

Analytic validity addresses how accurately and reliably the tool identifies disease among a person's relatives. The specific elements of analytic validity include sensitivity and specificity. Sensitivity is a measure of how well the family history tool identifies relatives who truly have the disease of interest, and specificity is a measure of how well the tool identifies the relatives who truly do not have the disease of interest. A few studies have attempted to measure the sensitivity and specificity of family history instruments by interviewing relatives and conducting medical record reviews. The validity of the instrument used to collect family history in the Utah study of CHD showed $77 \%$ sensitivity and $85 \%$ specificity. ${ }^{7}$ In a validation study of family history of diabetes, there was complete agreement between information about diabetic status reported by patients in a clinic and the information given by respective relatives in a follow-up interview. ${ }^{21}$ Disease that occurs at earlier ages and results in more severe morbidity will likely be reported more accurately than disease that occurs late in life and is less severe. Diseases for which there may be some stigma, such as schizophrenia or alcoholism, may be reported less reliably. The setting for the collection of family history information will also affect analytic validity. A take-home questionnaire that will allow individuals to confer with relatives or review family records will likely be more accurate than an interview that occurs on the spot. The evaluation of the analytic validity of a family history instrument should involve comparisons with some gold standard, such as can be done with medical records or direct interviews with living relatives. It should also include an assessment of the specific diseases included in the tool, the relationship of the relatives included (first- and second-degree), and the settings in which the tool is administered.

\section{CLINICAL VALIDITY}

Clinical validity addresses how well family history of disease can be used to stratify disease risk and predict future disease in a person. The specific elements of clinical validity include sensitivity, specificity, and negative and positive predictive value. Like predictive genetic testing, a family history tool is used to estimate the probability that a person will develop disease. With highly penetrant gene mutations such as the one that causes Huntington disease, a positive genetic test results in near $100 \%$ certainty that a person will develop the disease. For many other diseases where the causative genes are less penetrant, a positive test means that there is an increased probability of disease but that development of disease may be influenced by other genes and environmental factors. Likewise with a positive family history, a person may be at increased risk for disease above that of the population at large, but the interaction of genetic and environmental factors will ultimately determine whether or not the person develops disease.

In designing a family history tool that is useful in public health settings, there will be a trade-off between keeping it simple and collecting enough information to make prediction possible. A simple tool may not be able to distinguish between high and moderate risk. Issues that will need to be considered and evaluated include the collection of information on more than first-degree relatives, the list of diseases included in the tool, and the use of a classification system or algorithm for defining level of risk. When a person is adopted or has few relatives, the possibility of a family history rich in disease-specific information is obviously much reduced. The collection of family history information will also have to be evaluated in the context of additional screening information. Family history may have a synergistic effect in the presence of other known risk factors. For example, in a study of pancreatic cancer, the relative risk of pancreatic cancer associated with having a firstdegree family member with pancreatic cancer was 2.49 (95\% CI, 1.32-4.69), which was similar to the relative risk associated with ever smoking, 2.04 (95\% CI, 1.09-3.83). The relative risk increased to 8.23 (95\% CI, 2.18-31.07) for persons who ever smoked and who had a family member with pancreatic cancer diagnosed before age 60.22

Measuring the sensitivity and specificity of family history can be done using data from case-control or large cohort studies. Sensitivity can be estimated by examining the family history for a particular disease among a population-based group of people with that disease. Likewise, specificity can be estimated by examining family history for a particular disease among a population-based group of people without the disease. The positive predictive value can then be determined to provide information on the probability that a person will develop disease given a positive family history. Conversely, negative predictive value is the probability that people will not develop disease if they have a negative family history. Unlike sensitivity and specificity, the positive and negative predictive values of a family history tool depend on the prevalence rate of the disease in the population. If the prevalence of a disease is low, even a highly valid tool will yield a low predictive value. Establishing the clinical validity of family history tools will require research involving the use of the tools in different population groups. It will also require careful consideration of potential reporting bias in case-control studies. Affected people (cases) may be more likely to report a positive family history than are unaffected people (controls), resulting in an overestimate of predictive value. Reporting bias is also an issue that 
affects the assessment of analytic validity. Although the impact of differential recall on the results of case-control studies has been examined in general, ${ }^{23}$ few studies have assessed potential bias associated with family history and estimates of risk for specific disease. ${ }^{24}$

The contribution of family history to disease risk has traditionally been assessed in terms of relative risk; however, the attributable risk may be a better indicator of the utility of family history information. The population attributable risk is an estimate of the incidence of disease in a population that is associated with exposure to the risk factor, in this case, family history. ${ }^{25}$ To be useful for individuals, risk estimates from epidemiological studies need to be described in terms of absolute risk. People are more likely to understand their own probability of developing disease given certain risk factors than they are the relative or attributable risk of disease.

These concepts are illustrated in Table 3, where risk for colorectal cancer (CRC) is classified into three groups: 1) average risk (no first-degree relative with CRC), 2) moderate risk (a first-degree relative with CRC after age 50), and 3) high risk (two first-degree relatives with CRC regardless of age). The risk estimates for the average and moderate risk categories were obtained from analysis by Fuchs et al. ${ }^{26}$ of the Nurses' Health Study and the Health Professionals Study. The risk estimates for the high-risk group are presented as a range and were obtained from a population-based study in the United King$\operatorname{dom}^{27}$ and a review of the genetics of familial adenomatous polyposis (FAP). ${ }^{28}$ Individuals presenting with a family history of CRC in the high-risk category may be at risk of disease of unknown origin or one of several high-risk syndromes, including FAP and hereditary nonpolyposis colorectal cancer (HNPCC). ${ }^{29}$ People carrying an APC gene mutation for FAP are virtually certain to develop CRC (absolute risk approaching 1), usually by their mid-30s; yet FAP is rare (prevalence approximately 1/8000) and accounts for a very small share of $\mathrm{CRC}$ in the population (attributable fraction $<1 \%$ ). A moderate family history of $\mathrm{CRC}$, on the other hand, results in an absolute lifetime risk of about $6 \%$ for the individual, and perhaps $7 \%$ of CRC in the population. Unfortunately, the data for these risk estimates that describe the impact of family history on disease occurrence are not available for many of the diseases listed in Table 1. There are case-control studies that have compared the prevalence of family history between case and control groups, but population-based data are needed to calculate the absolute and attributable risks. Models based on population data, including family history, have been developed for risk prediction, such as the Gail and Claus models used to estimate lifetime risk for breast cancer. ${ }^{30,31}$

\section{CLINICAL UTILITY}

Clinical utility is an assessment of the impact and usefulness of the family history tool for individuals, families, and society. Perhaps the most important issue is whether family history information can be used as a motivator to change behavior. Given a tool that has reasonable analytic and clinical validity, would the classification of individuals into risk groups improve the effectiveness of available early detection methods and interventions? Are public health interventions more effective if they are targeted to high-risk groups? Are individuals more motivated to improve their health if they know they may be at higher risk than the average population? Would individuals in the average-risk groups become complacent and less likely to engage in healthy behaviors? Studies of behavior change have shown that just telling people that they are at risk of developing a disease is rarely sufficient to change behavior. ${ }^{32}$ Marteau and Lerman propose that people's motivation to change behavior may be increased if they believe that changing behavior can reduce risks and that they have the ability to change. ${ }^{14} \mathrm{~A}$ recent study of colorectal cancer found that a strong family history of cancer was associated with better adherence to sigmoidoscopy recommendations. ${ }^{33}$ And analysis of the Framingham Offspring Study found that mammography use was higher among women with a family history of breast cancer compared with women without a family history. ${ }^{34}$ More studies like these are needed to measure the extent to which knowledge of family history can influence beliefs and health promoting behaviors to prevent common chronic diseases.

Table 3

Risk estimates for colorectal cancer for three risk groups as defined by family history

\begin{tabular}{|c|c|c|c|}
\hline Risk group & Average & Moderate & High \\
\hline Risk factor & $\begin{array}{l}\text { No 1st-degree relative } \\
\text { with colorectal } \\
\text { cancer }{ }^{26}\end{array}$ & $\begin{array}{l}\text { Any } 1 \text { st-degree relative } \\
\text { with colorectal } \\
\text { cancer after age } 50^{26}\end{array}$ & $\begin{array}{l}\text { Two 1st-degree relatives with } \\
\text { colorectal cancer }{ }^{27,28}\end{array}$ \\
\hline $\begin{array}{l}\text { Prevalence of the } \\
\text { risk factor }\end{array}$ & $9 / 10$ & $1 / 10$ & $1 / 50-1 / 8,000$ \\
\hline Absolute risk & 0.04 & 0.06 & $0.20^{a}-\sim 1$ \\
\hline Relative risk & reference & 1.7 & $4.9-\sim 30$ \\
\hline $\begin{array}{l}\text { Attributable } \\
\text { fraction }^{b}\end{array}$ & - & 0.07 & $0.07-0.004$ \\
\hline
\end{tabular}

${ }^{a}$ Estimated based on a relative risk of 4.9 and compared with people with no family history.

${ }^{b}$ Calculated using Levin's formula ${ }^{37}$ for population attributable risk. 


\section{ETHICAL, LEGAL, AND SOCIAL ISSUES}

In addition to assessing the effect that knowledge of disease risk may have on people, there are ethical considerations that must be evaluated as well. Labeling a person as high- or moderate-risk for disease may have important psychological, social, and economic costs. The use of a family history tool for public health purposes could only be successful if people perceived greater benefit than risk associated with revealing family medical information, if there was no stigma associated with being at above average risk, and if there were interventions and options for behavior change that could make a difference in reducing morbidity and mortality. These characteristics of family history of disease will need to be evaluated for each disease that may be included in a family history tool and for different population and cultural groups.

\section{CONCLUSION}

Francis Collins has described a scenario in the year 2010 where a primary care physician could offer a healthy 23-yearold male patient a DNA screening test that would provide estimated lifetime and relative risks for developing certain common chronic diseases. ${ }^{35}$ If it was discovered that the person carried a genotype for a carcinogen metabolizing enzyme, for example, that put him at increased risk for lung cancer, then the patient could be encouraged to stop smoking or never start. An analogous risk profile could be developed based on family history information. Unlike a DNA-based test that may not be available until 2010 or later for establishing individual risk profiles, family history tools are available now.

Table 4 provides risk estimates for a hypothetical healthy 23-year-old male, based on information collected using a family history tool. The patient would be categorized as high risk for colorectal cancer, moderate risk for cardiovascular disease and diabetes, and at average risk for melanoma. Additional risk factor information, such as body mass index, smoking status, and ethnicity could be used to further refine the risk estimates and influence long-term management and prevention strategies. For the high colorectal cancer risk, referral of the family for genetic evaluation and possible testing would be appropriate. If a hereditary cancer syndrome could be defined, then more frequent colonoscopy would be recommended for susceptible family members and prevention strategies for other syndrome-associated cancers might be warranted (e.g., endo- metrial, ovarian, and gastric cancer associated with hereditary nonpolyposis colon cancer). If a cancer susceptibility gene mutation were identified and excluded in a family member, he/she could be reassured and average-risk screening guidelines could be recommended. In the absence of diagnosing a hereditary colon cancer syndrome, colonoscopy every 3 to 5 years beginning 10 years earlier than the earliest age of colorectal cancer onset in the family could be offered to the patient. For the moderate cardiovascular risk, the plan might include behavior changes that reduce the risk of cardiovascular disease and diabetes, such as maintaining a healthy weight and exercising, and participating in standard lipids screening and treatment. Given the average risk for melanoma, general recommendations for minimizing sun exposure and education regarding the characteristics of a skin malignancy would be appropriate.

In the scenario just described, family history information is used to customize disease prevention efforts and provide some added value to current public health efforts aimed at the population-at-large. To determine the feasibility, validity, and utility of this approach, we recommend the following actions. The first step would be to convene a workshop of experts to further explore the ideas we have outlined and develop a research agenda for designing studies and analyzing existing data to assess family history. A major component of the research would be to evaluate simple tools for collecting family health history that can be used in public health settings. Development of the tools would include considerations of what conditions and diseases to include, what relatives should be included, and how and where the tool would be administered. A classification scheme could also be developed that would group people into risk categories depending on the information collected. The data collection tools and classification scheme could then be evaluated for analytic validity and clinical validity under different settings. Once the validity of the tools has been established, hypotheses can be generated about the use of the family history information for improving health outcomes. Funding should then be made available for conducting public health research to test these hypotheses.

Aubrey Milunsky claims in his new book, Your Genetic Destiny, ${ }^{36}$ that "by knowing your genes, you can save your life." Until we have genetic tests that identify susceptibility genes and biomarker measures for most environmental exposures, family history information that reflects our shared genetic make-up and environment may be an effective means for pre-

Table 4

Preventive medical practice in 2002: Results of family history screening for a hypothetical, healthy 23-year-old male

\begin{tabular}{|c|c|c|c|c|}
\hline Condition & Family history & Risk group & Relative risk & Lifetime risk \\
\hline Cardiovascular disease & $\begin{array}{l}\text { One 1st-degree male relative diagnosed after } \\
\text { age } 60\end{array}$ & Moderate & 2.0 & $60 \%$ \\
\hline Colorectal cancer & $\begin{array}{l}\text { Two 1st-degree relatives, one with onset } \\
\text { before age } 50\end{array}$ & High & 8.0 & $50 \%$ \\
\hline Melanoma & None & Average & 1.0 & $<1 \%$ \\
\hline Diabetes type II & One 1 st-degree relative diagnosed after age 60 & Moderate & 5.0 & $30 \%$ \\
\hline
\end{tabular}

Adapted from Collins. ${ }^{35}$ 
dicting our risk of future disease. Family history information in combination with other known risk factors, such as diet, for example, could be used to provide more personalized information about our risk for common diseases. It remains to be seen whether this knowledge would lead to increased adoption of health promoting behaviors. Perhaps by knowing your family history, you can improve your health and save your life.

\section{References}

1. Yoon PW, Chen B, Faucett A, Clyne M, Gwinn M, Lubin IM, Burke W, Khoury MJ. The public health impact of genetic tests at the end of the 20th century. Genet Med 2001;3:405-410.

2. Rimoin DL, Connor JM, Pyeritz RE, editors. Principles and practices of medical genetics, 3rd ed. London: Churchill Livingstone, 1997:31.

3. Hedenfalk I, Duggan D, Chen Y, Radmacher M, Bittner M, Simon R, Meltzer P, Gusterson B, Esteller M, Kallioniemi OP, Wilfond B, Borg A, Trent J. Gene-expression profiles in hereditary breast cancer. N Engl J Med 2001;344:539-548.

4. Ishibe N, Kelsey KT. Genetic susceptibility to environmental and occupational cancers. Cancer Causes Control 1997;8:504-513.

5. Rockhill B, Kawachi I, Colditz GA. Individual risk prediction and population-wide disease prevention. Epidemiol Rev 2000;22:176-180.

6. Williams RR, Hunt SX, Heiss G, Province MA, Bensen JT, Higgins M, Chamberlain RM, Ware J, Hopkins PN. Usefulness of cardiovascular family history data for population-based preventive medicine and medical research (the Health Family Tree Study and the NHLBI Family Health Study). Am J Cardiol 2001;87:129-135.

7. Hunt SC, Williams RR, Barlow GK. A comparison of positive family history definitions for defining risk of future disease. J Chronic Dis 1986;39:809-821.

8. King RA, Rotter JI, Motulsky AG, editors. The genetic basis of common diseases. New York: Oxford University Press, 1992.

9. Scheuner MT, Wang SJ, Raffel LJ, Larabell SK, Rotter JI. Family history: a comprehensive genetic risk assessment method for the chronic conditions of adulthood. Am J Med Genet 1997;71:315-324.

10. Silberberg J, Fryer J, Wlodarczyk J, Robertson R, Dear K. Comparison of family history measures used to identify high risk of coronary heart disease. Genet Epidemiol 1999;16:344-355.

11. Hayflick SJ, Eiff MP, Carpenter L, Steinberger J. Primary care physician's utilization and perceptions of genetic services. Genet Med 1998;1:13-22.

12. Henderson LB, Scheuner MT. Suboptimal family history collection: an obstacle to genetic risk assessment and prevention. Am J Hum Genet 1998;63:A240

13. Acheson LS, Wiesner GL, Zyzanski SJ, Goodwin MA, Stange KC. Family historytaking in community family practice: implications for genetic screening. Genet Med 2000;2:180-185.

14. Marteau TM, Lerman C. Genetic risk and behavior change. $\mathrm{Br}$ Med J 2001;322: $1056-1059$.

15. Perera FP. Environment and cancer: who is susceptible? Science 1997;278:1068 1073.

16. Rose G. The strategy of preventive medicine. New York: Oxford University Press, 1992.

17. National Center for Health Statistics, Health-E Stat: http://www.cdc.gov/nchs/ fastats/overwt.htm, 1999.

18. Eberhardt MS, Ingram DD, Makuc DM, et al. Urban and rural health chartbook: health, United States 2001. Hyattsville, MD: Centers for Disease Control and Prevention, National Center for Health Statistics, 2001.

19. Centers for Disease Control, and Prevention. Physical activity trends: United States, 1990-1998. MMWR 2001;50:166-169.

20. Department of Health and Human Services, Secretary's Advisory Committee on Genetic Testing. Request for public comment on a proposed classification methodology for determining level of review for genetic tests. Fed Reg 2000;65:76643-76645

21. Kahn LB, Marshall JA, Baxter J, Shetterly SM, Hamman RF. Accuracy of reported family history of diabetes mellitus: results from San Luis Valley Diabetes Study. Diabetes Care 1990;13:796.

22. Schenk M, Schwartz AG, O’Neal E, Kinnard M, Greenson JK, Fryzek JP, Ying GS, Garabrant DH. Familial risk of pancreatic cancer. J Natl Cancer Inst 2001;93:640-644

23. Drews CD, Greeenland S. The impact of differential recall on the results of casecontrol studies. Int J Epidemiol 1990;19:1107-1112.

24. Silberberg JS, Wlodarczyk J, Fryer J, Ray CD, Hensley MJ. Correction for biases in population-based study of family history and coronary heart disease: the Newcastle Family History Study I. Am J Epidemiol 1998:147:1123-1132.
25. Last JM, editor. A dictionary of epidemiology, 3rd ed. New York: Oxford University Press; 1995:126.

26. Fuchs CS, Giovannucci EL, Colditz GA, Hunter DJ, Speizer FE, Willett WC. A prospective study of family history and the risk of colorectal cancer. $N$ Engl J Med 1994:331:1669-1674.

27. Sandhu MS, Luben, Khaw KT. Prevalence and family history of colorectal cancer: implications for screening. J Med Screen 2001;8(2):69-72.

28. Bodmer W. Familial adenomatous polyposis (FAP) and its gene, APC. Cytogenet Cell Genet 1999;86:99-104.

29. Lynch HT, Lynch JF. Hereditary nonpolyposis colorectal cancer. Semin Surg Oncol 200;18:305-313.

30. Gail MH, Brinton LA, Byar DP, Corle DK, Green SB, Schairer C, Mulvihill JJ. Projecting individualized probabilities of developing breast cancer for white females who are being examined annually. J Natl Cancer Inst 1989;81:1879-1886.

31. Claus EB, Risch N, Thompson WD. Autosomal dominant inheritance of early-onset breast cancer: implication for risk prediction. Cancer 1994;73:643-651.

32. Leventhal $\mathrm{H}$, Benyamini $\mathrm{Y}$, Brownlee $\mathrm{S}$, et al. Illness representations: theoretical foundations. In: Petrie KJ, Weinman JA, editors. Perceptions of health and illness. Amsterdam: Harwood, 1997.

33. Codori AM, Petersen GM, Miglioretti DL, Boyd P. Health beliefs and endoscopic screening for colorectal cancer: potential for cancer prevention. Prev Med 2001;33: $128-136$.

34. Murabito JM, Evans JC, Larson MG, Kreger BE, Splansky GL, Freund KM, Moskowitz MA, Wilson PW. Family breast cancer history and mammography. Am Epidemiol 2001;154:916-923.

35. Collins FS. Shattuck lecture: medical and societal consequences of the Human Genome Project. N Engl J Med 1999;341:28-37.

36. Milunsky A. Your genetic destiny. Cambridge, MA: Persues, 2001.

37. Levin ML. The occurrence of lung cancer in man. Acta Unio Int Contra Cancrum 1953;19:531.

38. Ciruzzi M, Pramparo P, Rozlosnik J, Zylberstjn H, Delmonte H, Haquim M, Abe casis B, de La Cruz Ojeda J, Mele E, La Vecchia C, Schargrodsky H. Frequency of family history of acute myocardial infarction in patients with acute myocardia infarction. Argentine FRICAS (Factores de Riesgo Coronario en America del Sur) Investigators. Am J Cardiol 1997;80:122-127.

39. Silberberg JS, Wlodarczyk J, Fryer J, Robertson R, Hensley MJ. Risk associated with various definitions of family history of coronary heart disease: the Newcastle Family History Study II. Am J Epidemiol 1998;147:1133-1139.

40. Pharoah PD, Day NE, Duffy S, Easton DF, Ponder BA. Family history and the risk of breast cancer: a systematic review and meta-analysis. Int J Cancer 1997;71:800-809.

41. Collaborative Group on Hormonal Factors in Breast Cancer. Familial breast cancer: collaborative reanalysis of individual data from 52 epidemiological studies including 58,209 women with breast cancer and 101,986 women without the disease. Lance 2001;358:1389-1399.

42. Cerhan JR, Parker AS, Putnam SD, Chiu BC, Lynch CF, Cohen MB, Torner JC, Cantor KP. Family history and prostate cancer risk in a population-based cohort of Iowa men. Cancer Epidemiol Biomarkers Prev 1999;8:53-60.

43. Steinberg GD, Carter BS, Beaty TH, Childs B, Walsh PC. Family history and the risk of prostate cancer. Prostate 1990;17:337-347.

44. Holman CD, Armstrong BK. Pigmentary traits, ethnic origin, benign nevi, and family history as risk factors for cutaneous malignant melanoma. J Natl Cancer Inst 1984;72:257-266.

45. Cutler C, Foulkes WD, Brunet JS, Flanders TY, Shibata H, Narod SA. Cutaneous malignant melanoma in women is uncommonly associated with a family history of melanoma in first degree relatives: a case-control study. Melanoma Res 1996;6:435-440.

46. Klein BE, Klein R, Moss SE, Cruickshanks KJ. Parental history of diabetes in a population-based study. Diabetes Care 1996;19:827-830.

47. Bjornholt JV, Erikssen G, Liestol K, Jervell J, Thaulow E, Erikssen J. Type 2 diabetes and maternal family history: an impact beyond slow glucose removal rate and fasting hyperglycemia in low-risk individuals? Results from 22.5 years of follow-up of healthy nondiabetic men. Diabetes Care 2000;23:1255-1259.

48. Keen RW, Hart DJ, Arden NK, Doyle DV, Spector TD. Family history of appendicular fracture and risk of osteoporosis: a population-based study. Osteoporos In 1999;10:161-166

49. Fox KM, Cummings SR, Powell-Threets K, Stone K. Family history and risk of osteoporotic fracture: Study of Osteoporotic Fractures Research Group. Osteoporos Int 1998;8:557-562.

50. Tariq SM, Matthews SM, Hakim EA, Stevens M, Arshad SH, Hide DW. The prevalence of and the risk factors for atopy in early childhood: a whole population birth cohort study. J Allergy Clin Immunol 1998;101(5):587-593.

51. Genes for asthma? An analysis of the European Community Respiratory Health Survey. Am J Respir Crit Care Med 1997;156:1773-1780. 